\title{
¿HABRÁ ALGUNA MANERA DE NO ARRUINAR LAS CLASES DE ARTE?
}

\section{IS THERE A WAY NOT TO RUIN ART CLASSES?}

Julio Schinca / julioschinca2001@yahoo.com.ar

Facultad de Artes. Universidad Nacional de La Plata. Argentina

Recibido: 11/10/2019 | Aceptado: 4/3/2020

Reseña a Daniel Belinche (2017). Diez formas de arruinar una clase. La Plata, Argentina: Papel Cosido, Facultad de Artes de la Universidad Nacional de La Plata y Malisia editorial, 149 páginas

\section{RESUMEN}

Diez formas de arruinar una clase es un libro del Dr. Daniel Belinche, en el que se adentra en las cuestiones esenciales de la enseñanza del arte hoy. Nos interpela como docentes a replantearnos nuestras certezas dentro y fuera del aula. A través de sus páginas, mediante el relato fluido de ejemplos y la incorporación de referencias de obras, artistas, pedagogos, pensadores e investigadores, surgen las conclusiones que se ofrecen como rudimentos para no claudicar en el intento de «no arruinar una clase de Arte».

\section{PALABRAS CLAVE}

Enseñanza del arte; docencia; conocimiento; experiencia artística

\section{ABSTRACT}

Ten Ways to Ruin a Class is a book by Dr. Daniel Belinche that delves into the essential questions of art teaching today. It challenges us as teachers to rethink our certainties inside and outside the classroom. In its pages, through the fluid narration of examples and the incorporation of references to works, artists, pedagogues, thinkers and researchers, emerge the conclusions that are offered as rudiments to avoid giving up in the attempt to «not ruin an Art class».

\section{KEYWORDS}

Art education; teaching; knowledge; artistic experience 


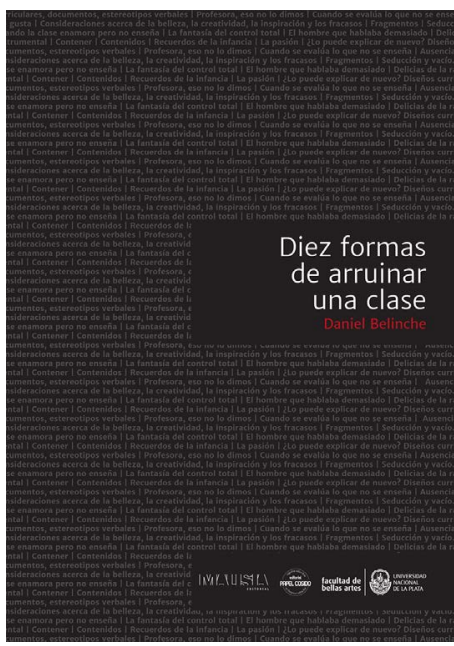

Daniel Belinche es un artista. Es un profesional con un recorrido vasto en la gestión educativa tanto en la Universidad Nacional de la Plata (UNLP), en la provincia de Buenos Aires donde fue Subsecretario de Educacióncomo a nivel nacional -fue Secretario del Consejo Federal de Educación del Ministerio de Educación de la Nación-. Como músico, ha compuesto, tocado y grabado para tantísimos espectáculos. Como investigador, ha escrito libros y numerosos artículos. Ha dado conferencias en el país $y$ en el exterior. Sin embargo, $y$ a pesar de sus tantas ocupaciones, nunca resignó uno de sus espacios favoritos: el de profesor de música de la Facultad de Artes de la UNLP.

Desde ese lugar, desde esa práctica docente, es desde donde se cimenta la respuesta contundente a la pregunta por la enseñanza del arte. Y Belinche la va desplegando deliciosamente en Diez formas de arruinar una clase. Cada capítulo nos introduce en el mundo del aula, el "escenario natural» donde acontecen cotidianamente la enseñanza y los aprendizajes. Casi como crónicas de viaje, página tras página, va develando anécdotas, con sus paisajes áulicos, personajes, obras y circunstancias que rodean a la acción pedagógica.

Obviamente, no son escritos propios de una bitácora o una novela, sino que mediante los recursos de la brevedad y la profundidad en el abordaje de los temas, la ejemplificación ingente y la cita de fuentes documentadas, va urdiendo sólidos fundamentos que alumbran zonas opacas en las prácticas didácticas del arte.

¿Qué problemas desafían hoy a la enseñanza artística? Cuestiones como la belleza, la fragmentación como interrupción, la indagación sobre los contenidos propios del arte, la 
propuesta de clase que enamora pero no enseña, la fantasía del control total, las tradiciones verbales estereotipadas que devienen de los diseños curriculares y documentos escolares, son algunas de las temáticas desde las cuales se interroga lo dado, lo procedimental, lo aferrado al imaginario social como rémora de una "modernidad" (Díaz, 2000) que hace rato se viene transformando.

Al mismo tiempo, una certeza se va hilvanando fluidamente en la escritura, es transversal a todo el texto y se expresa como una afirmación por la negación: no simplificar la complejidad del objeto de enseñanza, el arte.

Mediante las narraciones y el análisis de situaciones cercanas a cualquier docente de arte frente a sus estudiantes, Belinche dilucida rasgos comunes de la práctica, como la sobreargumentación: ese mecanismo pedagógico que opera como una reducción que solo informa a quien intenta aprender. De esta manera, la experiencia se empobrece.

Una clase que solo ofrece cantidades profusas de información, desplaza al sujeto y lo deja afuera de "la situación que lo habilita a profundizar y a comprender" (Belinche, 2017, p. 11). La narración informativa no reemplaza a la experiencia y al conocimiento artístico que conlleva tocar y cantar una canción, bailar, dibujar, pintar o actuar una escena teatral.

Finalmente, la lectura de Diez formas de arruinar una clase se nos presenta como una experiencia fruto de la experiencia, como una invitación a repensar la enseñanza del arte en todas sus dimensiones: desde el enfoque pedagógico, las propuestas didácticas en el aula, los temas propios de la disciplina, los estereotipos que la atraviesan, hasta los objetivos y los criterios de evaluación. Es, sin lugar a dudas, una obra necesaria que fortalece los argumentos y que retroalimenta las ganas para seguir dando más y mejores clases de arte.

\section{REFERENCIAS}

Belinche, D. (2017). Diez formas de arruinar una clase. La Plata, Argentina: Papel Cosido, Facultad de Artes de la Universidad Nacional de La Plata y Malisia editorial. Recuperado de

http://papelcosido.fba.unlp.edu.ar/libros/libro-diez-formas-arruinar.html

Diaz, E. (2000). Posmodernidad. Ciudad Autónoma de Buenos Aires, Argentina: Biblos. 